\title{
People's Biodiversity Register [PBR]: A Community Based New Venture in Odisha to Document Natural Resources
}

\author{
Om Prakash Rautaray ${ }^{1, *}$, Rudra Narayan $\operatorname{Pradhan}^{2}$, Prasanna Behera ${ }^{3}$, Hemanta Ku. Sahu ${ }^{4}$ \\ ${ }^{1}$ GA Plot no -537, Bharatpur, Bhubaneswar, Pin-751003, Odisha \\ ${ }^{2} \mathrm{O} / \mathrm{o}$ - Regional Chief Conservator of Forests Angul, Odisha, India \\ ${ }^{3}$ Nature Environment \& Wildlife Society (NEWS) Angul, Odisha, India \\ ${ }^{4}$ Department of Zoology, North Orissa University, Baripada -757003, India \\ *Corresponding Author: omprakash1972@gmail.com
}

Copyright (C) 2014 Horizon Research Publishing All rights reserved.

\begin{abstract}
The Government of India introduced the "Biological Diversity Act 2002", in the year 2002 and the "Biological Diversity Rules" in the year 2004. Accordingly all state governments would have to constitute biodiversity boards and frame their own state specific Biological Diversity Rules. With this enforcement, the Government of Odisha has published the Biological Diversity Act, 2002 in the local vernacular language and constituted the Odisha Biodiversity Board. Apart from this the Odisha Government framed the "Odisha Biological Diversity Rules, 2012". But, there still wasn't any initiative by the State Government to document traditional knowledge \& biological resources, though Odisha is rich in biodiversity. In the year 2009-2010, an initiative was taken up by the Odisha Forestry Sector Development Project (OFSDP), an external aided project of Forest \& Environment Department and its General Consultants (GC) to document the biological diversity of Satkosia Tiger Reserve and its periphery areas with the participation of local people by use of their traditional wisdom \& grassroots level forest officials much before the publication of the Odisha Biological Diversity Rules, 2012. This article articulates the complexities, objectives , modules, pitfalls, benefit sharing and challenges of the experiment as stated above by using People Biodiversity Register to document the biodiversity resources.
\end{abstract}

Keywords People Biodiversity Register, Bio Diversity Act, Bio Diversity Rules, Satkosia Tiger Reserve, Odisha Forestry Sector Development Project

\section{Introduction}

The demand for accurate forecasting of the effects of global warming on biodiversity is growing, but current methods for forecasting have limitations. Now that it is widely accepted that global warming is happening, there is a growing demand for accurate forecasts of its effects, and much concern about its effects on biological diversity. Specialists know that theoretical models of these effects are limited-although useful in certain contexts when all the provisions, preconditions, and limitations of a given model are understood-and should not be taken literally. Often, however, the media do not convey these caveats. It is no wonder that policymakers and the general public are confused. The purpose of an environmental forecast is either to support a decision process or to test a scientific hypothesis. To support a decision process, it must be clear which decisions the forecast expects to improve. To mitigate the effects of global warming on biodiversity, two distinct kinds of actions are needed: long-term actions, such as reducing emissions of greenhouse gases, and short-term ones, such as designing an appropriate nature reserve. For the second action, documentation of biodiversity resources making the stakeholders involved in the whole process is essential to disseminate the environmental awareness and knowledge at the grass root level.

On the other hand, we live in times of profound change, of unprecedented challenges and opportunities; we are in the midst of a biotechnology revolution, an information revolution and, alas an environmental crisis. We also live in a world that is becoming increasingly polarized with rich against poor nations; with the elite on one side and the disempowered on the other.

Humanity has responded to these changes in many ways; one is by accepting entirely new ways of managing living resources. These resources were till recently viewed as a common heritage of mankind. Now they are subject to two, somewhat conflicting systems of rights, embodied in the Convention on Biological Diversity and the General Agreement on Trade and Tariff. On the one hand they are viewed as sovereign property of nation states. On the other, they are being accepted as an intellectual property of 
enterprises which have manipulated or even simply discovered them. Intellectual property rights are also being established over the knowledge of many types of uses of these resources.

These are important challenges in all this for a country like India, rich as we are in biodiversity resources, and folk and traditional knowledge of properties and uses of these resources. Unfortunately, India is a poor country in terms of well-organized, well-substantiated, well-documented information. In the current information age, it is imperative that we overcome this weakness and establish sound systems of information on our biodiversity resources and their known uses. Such a system is especially needed to protect the interests of the ecosystem people of India, people who have played such a vital role in conserving the country's biodiversity, in augmenting it through evolving thousands of varieties of cultivated plants and domesticated animals, and in developing a vast body of knowledge about their sustainable use.

The Foundation for Revitalization of Local Health Traditions (FRLHT), working in collaboration with the Centre for Ecological Sciences (CES), at the Indian Institute of Science (IISc), has been involved in formulating an innovative programme to address this challenge. It goes by the name of People's Biodiversity Register, (PBR), and seeks to document the knowledge of occurrence, practices of propagation, sustainable harvests and conservation, as well as economic uses of biodiversity resources that resides with India's local communities.

\section{Place of Experiment}

There are 11 protected areas [sanctuaries in Odisha] managed by Forest Department (FD), Government of Odisha (GoO) and many more sacred groves/ community reserves [not declared] traditionally managed by the local community. The biodiversity of the areas are conserved by the local community for their cultural and spiritual need with their traditional wisdom. But till date there is no inventory is made for the same with the participation of people and their traditional knowledge. An attempt has been made for systematic documentation of the biodiversity of the Satkosia Tiger Reserve [PA] and Mandargiri-Kalima RF [Proposed Biodiversity Heritage site] in Angul district of Odisha.

\section{Biodiversity Resources}

Biodiversity resources may be defined as the variety of living organisms and their products of human utility other than as bulk material resources such as food for humans, fodder for domesticated animals, energy sources like fuel wood, nutrient sources like dung and leaf manure and structural material such as bamboo, cane and timber. Biodiversity resources are biological materials used directly or in forms essentially derived there from as sources of special chemicals such as pharmaceuticals, fragrances, flavors, dyes and as genetic material underlying the production of such special chemicals as well as for enhancing the production of bulk material such as food or fiber through conferring on the concerned organisms such properties as higher growth rate, changed growth form or disease resistance.

Biodiversity resources also include living organisms or their products used for purposes of scientific investigations. Thus whether or not a particular material is to be viewed as a biodiversity resource depends on the end-use e.g. a Byadagi chilly may either be used as a food resource, or alternatively as a biodiversity resource for (i) the extraction of the red dye, or (ii) as a source of genetic information for the production of the red dye.

This Programme had its origins in the OFSDP [Odisha Forestry sector Development Project] implemented by Satkosia Tiger Reserve (STR). As evolved through these exercises, the People's Biodiversity Register is expected to serve (a) as a tool to document, monitor and provide information for sustainable management of local biodiversity resources; (b) as a tool to promote biodiversityfriendly development in the emerging process of decentralized management of natural resources; (c) as a tool to establish claims of individuals and local communities over knowledge of uses of biodiversity resources and to bring to them an equitable share of benefits flowing from the use of such knowledge and such resources; (d) as a tool for teaching environment and biology, and finally (e) as a tool to perpetuate and promote the development of practical ecological knowledge of local communities and of traditional "slow" sciences such as Ayurveda medicine.

PBR is a program in tune with the objectives of the Convention on Biological Diversity, urging all parties, including India and some 150 other countries to:

- respect, preserve and maintain the knowledge, innovations and practices of indigenous and local communities embodying traditional lifestyles relevant for the conservation and sustainable use of biological diversity;

- promote the wider application of such knowledge, innovations and practices with approval and involvement of the holders;

- encourage the equitable sharing of the benefits arising from the use of such knowledge, innovations and practices.

\section{Dealing with Complexity}

The so-called scientific forest management has overwhelmed and displaced the traditional systems of management of village woodlots. The modern intellectual property rights regimes have arisen hand in hand with modern science, so that the criteria prescribed for obtaining patent protection are tailored to the methodologies of say Allopathy and would reject any claims by Ayurveda. But, 
Allopathy is not at all averse to picking up knowledge from Ayurveda and Unani sciences. After all, quinine was derived from an age old remedy of Amerindians of Andes and reserpine from tribal medicine from Kerala. Most recently, an American patent has been granted on the use of turmeric powder as an antiseptic against wounds an age-old cure from India.

\section{The Challenges}

This then is the present scenario with many contradictions when dealing with such complex systems as human health or natural forest or pond ecosystems. The modern sciences dealing with such complex systems continue to benefit greatly from knowledge and practices of traditional indigenous science systems, but refuse to give them any real credit or share with them profits of commercial exploitation of knowledge.

The results are tragic - they are a steady erosion of knowledge and practices of traditional indigenous science systems - knowledge and practices that still have much to offer to humanity. That poses before us a great challenge - of how to establish a relationship of mutual respect between the two systems, how to synthesize the knowledge and practices of modern and traditional science, of how to ensure proper sharing of benefits and of control over natural resources amongst them. There are two important contexts in which this needs to be accomplished; firstly, in the context of knowledge and practices of uses of living resources e.g. medicinal uses of herbs or growing of a particular salinity resistant variety of paddy; and secondly, in the context of sustainable use and conservation of these living resources, maintaining, for instance, traditional systems of sustainable grazing of pastures or harvests of village woodlots, or protection of sacred groves and ponds.

Much needs to be done in many different ways to address these challenges. One component of this has involved careful, systematic documentation. The currently dominant system of modern science thrives on well specified, carefully recorded information. One of the grave disadvantages of traditional science is that its information base is fuzzy, incomplete and fragmented. It is vital that traditional sciences too develop a proper information base - without such a base they cannot work towards developing a symbiotic relationship with the modern sciences, to move towards claiming a proper share of commercial profits.

Some may view this as surrender to modern sciences. That is not so. The strength of traditional sciences lies in their enormous store of information of complex natural systems be they human health or forest or pond ecosystems. That this great store of information is fuzzily defined and poorly organised is a weakness that needs to be overcome for it to claim its rightful place in human affairs. This is the task that the People's Biodiversity Register programme attempts to take up.

\section{Objectives of the PBR}

The People's Biodiversity Register is a programme of organizing information available in the domain of slow science on the status, uses and management of the living resources. This is the information with practical ecologists, people who deal with living resources as a part of their daily subsistence activities - as grazers, as fisher folk, as basket weavers, hunters etc. It is information with simple folk, who are nevertheless specialists of slow science, such as tribal medicine men or say healer, or expert honey gatherers. It is also information with more sophisticated practitioners of slow science such as physicians trained in Ayurvedic colleges. The information may be purely orally transmitted or contained in palm leaf manuscripts or in printed Ayurvedic texts. The information may be guarded as secret, as certain herbal remedies are or may be very widely known as the use of turmeric as an antiseptic is all over India. This information may be documented in full, or as claims that only partially reveal the information. It needs to be collated, verified, synthesized and made available to the society at large, as well as fed back to the village communities.

The objectives of the programme would thus embrace the creation of decentralized countrywide databases on:

a) Status of biodiversity resources such as populations of medicinal plants, cultivars of fruit trees or freshwater fishes.

b) Various factors such as harvests from natural populations, changes in agricultural practices or discharge of industrial effluents, affecting the biodiversity resources.

c) Ongoing involvement of local communities/ individuals in sustainable use and conservation of biodiversity resources, such as systems of regulated grazing on pastures, maintenance of varieties of fruit plants like jackfruit on farm bunds or protection of fish in sacred ponds.

d) Local knowledge, widely shared and publically disclosed of properties and uses of biodiversity resources e.g. Drought-resistance of a certain cultivar, methods of preservation of food or use of certain plants in treating human or livestock diseases.

e) Local knowledge only partially disclosed; for instance, a claim that a particular medicine woman knows of a cure for asthma.

The programme would also attempt to:

f) Validate the information thus recorded; for instance, through crosschecking with other published information sources.

g) Create a network of decentralized databases, ultimately linking them to a consolidated national data base which would give full credit to the origin of information at the level of an individual, a community or a village panchayat. 
h) Feed pertinent information, such as volume of trade and prices of medicinal plants back to the local communities.

\section{End Uses}

We hope that the creation of such a countrywide decentralized yet networked system of information of slow science stream will serve several important purposes. It will for the first time create a machinery for monitoring the fate of a variety of biodiversity resources, be it medicinal plants, land-races of crops, breeds of regional livestock, or wild relatives of cultivated plants throughout the country. Such information could then form the basis of a strategy for the conservation of these resources.

Such an information system giving full and proper credit to informants would serve to give recognition and encouragement to the practical ecologists everywhere, many of whom are formally uneducated, yet have a deep fund of knowledge about the living world and its human uses.

This would also be a system of properly recording and establishing links amongst the many different strands of more formal systems of slow science, such as the Ayurvedic traditions of Kerala and Western Himalayas or the Siddha medicine of Tamilnadu and the Tibetan medicine of Sikkim.

Such an information system is also essential to begin a process of drawing on a part of the commercial profits made from further development of this broad base of slow science. There could be several ways of tapping such profits. Biodiversity-based enterprises may be charged some fees for accessing these information bases. They may pay a cess on their sales. Such income may be deposited into a National Biodiversity Fund which may be used to reward individuals, communities or village panchayats for their contributions towards:

a) Ongoing conservation of biodiversity resources on their private lands/ waters or on public lands/ waters within their jurisdiction.

b) Recording of practical ecological knowledge.

c) Recording of more systematised slow science, such as locally available manuscripts on Siddha system of medicine.

Additionally, the information system could help individual entrepreneurs establish contacts with claimants who do not fully disclose their knowledge. The two may then negotiate and decide on equitable sharing of benefits of possible commercial exploitation of such knowledge by entering into an appropriate Information or Material Transfer Agreement.

\section{Benefit Sharing}

These suggestions involve making important choices in the context of sharing of benefits flowing from commercial exploitation of the biodiversity resource base and knowledge of its uses in the "slow" science stream.

The first choice relates to rewarding for creation and maintenance of biodiversity, particularly in terms of cultivars of crops and land races of livestock, but also through systems such as protection to sacred groves, ponds or individual species. We may either focus on contributions made in the past or on the ongoing efforts. To assess ongoing contributions is easier; it may be based on recording of current stocks of biodiversity resources through the People's Biodiversity Registers. It would help promote in-situ conservation in years to come if we can organise a system of rewards linked to actual performance through yearly monitoring and updating of this information. We favour this alternative rather than get embroiled in the much more complicated task of deciding on past contributions and levels of rewards that they merit.

The second choice relates to rewarding of knowledge of uses. Where this is recorded only as claims, the option is clearly open for individual entrepreneurs to contact the claimants and work out mutually acceptable terms of sharing of benefits. But a vast amount of such knowledge is more widely shared within the community. It would then be very difficult to decide on who should have claims to the benefits to be shared. Nevertheless, such knowledge should surely be put to efficient use and rewarded. We suggest that in this case we should not aim at establishing specific one-to-one links amongst the knowledge and its use. Rather, we should attempt to raise a broad based National Biodiversity Fund from a cess on the whole spectrum of biodiversity based enterprises, whether it be seeds, pharmaceuticals or cosmetics. Proceeds from this fund could then be used to reward recording of knowledge of uses of biodiversity resources as evident from the People's Biodiversity Registers.

This may set up a healthy competition amongst various Panchayat bodies in the country to record as much as possible to attract awards. This could in turn promote the growth of biodiversity-based enterprises which would bring in more money to the National Biodiversity Fund.

\section{Possible Pitfalls}

It is important to anticipate two possible dangers in this whole exercise and work out measures to contain them from the very beginning. These are that the availability of easily accessible data bases may promote:

a) Over-harvest and depletion of biodiversity resources.

b) Usurpation of knowledge of uses of biodiversity resources without equitable sharing of benefits.

It is important to point out that both these processes are rampant today. Commercial interests are able to locate resources, e.g. medicinal plant stocks such as Mappia foetida of Western Ghat or Taxus buccata of Himalayas, and prompt their overexploitation. But in the total absence of organised information we are unable to monitor these trends. The information on stocks of biodiversity resources contained in 
the PBR would facilitate such monitoring and institution of measures to check them.

Furthermore, linking the stocks of biodiversity resources to rewards for ongoing contributions to conservation could create an effective stake for local communities to participate in programmes of conservation.

Similarly, for centuries the larger society has absorbed information on uses of biodiversity from the local communities and applied it with no thoughts of benefit sharing. After all Ayurveda itself is in part a synthesis of older tribal traditions. A great deal of such information has been recorded in a series of publications beginning with Watt's Wealth of India series of 19th century, going on to today's computerised data base called Napralert housed in Chicago. Modern pharmaceutical enterprises or seed companies also have their own on-going programmes of acquiring such information.

But in none of these is due credit given to the individuals/ communities/ panchayats making available such information. Assignment of such credit requires proper documentation and only a programme like the PBR could create such documentation. Of course we must supplement the documentation with legal provisions to properly direct the sharing of benefits. Nevertheless, there is no likelihood of any proper sharing of benefits ever taking off in the absence of good documentation.

To reiterate, the exercise of documentation in itself would be an important boost to the whole stock of knowledge residing today with the practical ecologists and other practitioners of slow science. But the full benefits of the information system would flow only when this is complemented by a system of open, public participation in conservation efforts and a just sharing of benefits flowing from biodiversity-based enterprises.

\section{Modules}

The People's Biodiversity Register would be prepared in relation to some specified human community of a few tens to a few thousands of households, generally falling within the jurisdiction of a single panchayat (= village council) and for the area from over which they gather the bulk of biological resources such as fuel wood or bamboos.

It would comprise of the following ten modules:

Peoplescape: Different segments of the concerned human communities and their relationship to the local base of natural, in particular, living resources.

Landscape: The local mosaic of different kinds of land and water habitats from over which the concerned people bring in most of living resouces such as fuel wood, dung, medicinal herbs, small timber, cane, reeds, bamboos etc.

Mindscape: Extent and distribution of knowledge relating to occurence, practices of propagation and harvest and uses of biodiversity resources amongst different segments of local human communities and held by particularly knowledgeable individuals.
Lifescape: Levels of abundance of different elements of biodiversity, in particular those groups with which local communities are familiar in different elements of the landscape and waterscape.

World in Flux: Ongoing changes in the local landscape, waterscape and lifescape and the forces driving these changes.

Utilisation: Ongoing economic transactions involving local biodiversity resources and the role of local people in these transactions. Perceptions of local people as to how fair such transactions are and how more equitable relationships may be established.

Nuturing Diversity: Local practices of sustainable use, conservation and restoration of biodiversity resources.

Marching on: Local community perceptions of ongoing conservation and development efforts.

Lifestyle: Personal aspirations of local people and how these would affect their relationship with the natural, especially the living world.

Choices: Local people's perceptions of options for development and management of the natural resource base in a biodiversity friendly fashion.

\section{Actors}

The People's Biodiversity Register exercise should involve three distinct set of actors:

a) Local people and their political institutions such as Gram Panchayat, Taluk Panchayat and Zilla Panchayat (village, country and district councils).

b) Government agencies involved with development and management of the natural, in particular, living resources such as state departments of agriculture, animal husbandry, fisheries, forestry, horticulture, irrigation and mining.

c) Educational and scientific institutions including local High Schools and Colleges, Universities, Research Institutions, State and District Councils of Science and Technology and programmes such as district-level centers of Natural Resource Data Management System.

The programme may be coordinated by the State (and constituent District) Councils of Science and Technology working with the local High Schools and Colleges. The basic data collection could be an exercise by local high school and college students under the guidance of science/ biology teachers based on field work as well as individual and group discussions with members of local community, especially knowledgeable individuals.

The District Councils of Science and Technology or the district level Natural Resource Data Management System Centres could then organize verification, collation and synthesis of the data. The basic People's Biodiversity Registers in local languages should be deposited with concerned village panchayats, schools and colleges and be open to scrutiny by all interested parties. Commercial 
enterprises wishing to access this information may do so on payment of a fee and on signing an appropriate agreement with reference to benefit sharing.

In the long run, it would be desirable to involve institutions of local self-governance, the panchayats, in a more active role in the whole exercise. It would also be desirable to constitute local academies of ethnosciennces involving especially knowledgeable practical ecologists such as fishermen, or practitioners of slow science such as medicine women, and give them a significant role in the whole exercise.

\section{Conclusions}

People's Biodiversity Register is a projection to fill the gap between knowledge \& ignorance and rich \& poor. It is certainly a tool of regional as well as national development with the practical involvement of rural people in a participatory mode. At the pipe end, it addresses the concerns of environmental crisis from the household to global level i.e. biodiversity loss, climate change and global warming.

\section{REFERENCES}

[1] Gadgil, M (1996) Peoples Biodiversity Register : a record of India's wealth, Amruth Spl. Suppl. 1-16

[2] Gadgil, $M$ and Rao, P.R.S., Utkarsh, G, Chhatre, A and members of people's biodiversity initiatives (2002) New Magazine for old Knowledge: Peoples Biodiversity Registers program, Ecological Applications 10(5), 1307-1317.

[3] Srishti Jigyaasa Pariwar (1998) Let the people speak, The Hindu Survey of Environment '98, 101-137

[4] Gadgil, M, Berkes, F., and Folke, C (1993) Indigenous knowledge for biodiversity conservation, Ambio 22, 151-156

[5] Achar, K.P. 1997. Documentation of People's Knowledge and Perceptions About Biodiversity and Conservation, People's Biodiversity Register, Shri Bhuvanendra College, Karkala, Dakshin Kannada, Karnataka, India.

[6] Gadgil, M and Rao, P.R.S. (1998) Nurturing Biodiversity: An Indian Agenda, Center for Environmental education, Ahmedabad.

[7] Swain, N and Sutar, P (2011) Implementation of Biological Diversity Act in India : An Overview with Case Studies, Regional Centre for Development Cooperation ( RCDC), Bhubaneswar, Odisha, India and supported by Supported by: Misereor-KZE, Germanay

[8] Biological Diversity Act 2002, Ministry of Environment and Forests. Government of India

[9] Revised PBR Guidelines 2013, (Based on the guidelines issued by NBA in 2009), National Biodiversity Authority, 5th Floor, TICEL Bio Park, Taramani, Chennai 600 113, Tamil Nadu, India

[10] Regional Centre for Development Cooperation ( RCDC), Bhubaneswar, Odisha (2011), Proceedings of the State-level Consultation on Biodiversity Conservation \& Bio resource Governance

[11] Perspectives on Biodiversity - A Vision for Mega diverse Countries. Published by Ministry of Environment and Forests, Govt. of India. 2005. Pg.375-396

[12] Odisha Biological Diversity Rules, 2012, Government of Odisha, Forest and Environment Department, Notification No 10. F(TR)-52/2012 - 22461/ F\&E, dtd. 03-12-2012 